
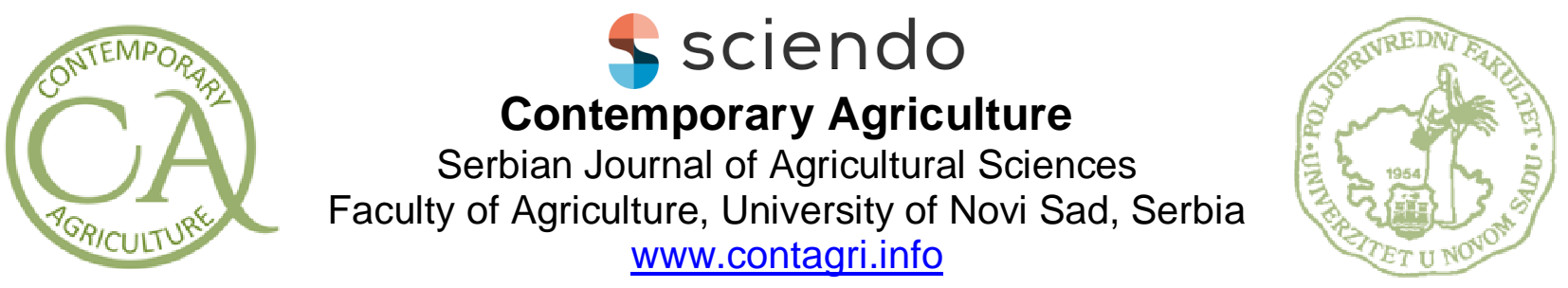

Original scientific paper

UDC: 582.998 .14

DOI: 10.2478/contagri-2020-0005

\title{
STATISTICAL ANALYSIS OF THE PHYSICOCHEMICAL PARAMETERS OF OLIVE (OLEA EUROPAEA L.) ECOTYPE OILS IN THE OASIS REGION OF DEGACHE (TUNISIA)
}

\author{
FATHI BEN AMAR ${ }^{1 *}$, SIHEM BEN MAACHIA ${ }^{2}$, MOHAMED AYADI ${ }^{1}$ \\ ${ }^{1}$ Olive Tree Institute. Airport Road, Km 1.5, PO Box 1087. 3000 Sfax, Tunisia (www.iosfax.iresa.agrinet.tn) \\ ${ }^{2}$ Regional Center of Research on Oasis Agriculture. PO Box 62, Tozeur road, km 1, Degache, Tozeur, Tunisia \\ ${ }^{*}$ Corresponding author: fathibenamar@yahoo.fr
}

\begin{abstract}
SUMMARY
A total of seventeen olive ecotypes were identified in the oasis region of Degache (Tozeur, Tunisia). The following physicochemical parameters of their oils were studied: acidity, refraction index, polyphenol, chlorophyll and carotene contents, oleic, palmitic and linoleic acid levels and the UV absorbance (K232 and K270). The acidity, K232 and K270 parameter values were used to classify most of the olive oils considered as 'extra virgin'. The highest carotene, chlorophyll and polyphenol contents of the olive oils examined were found to be $13.60 \mathrm{ppm}, 9.10$ ppm and 796 ppm, respectively. The oleic acid level of the olive oils considered ranged between 47\% and 73\%, whereas the palimtic acid level ranged between $11.8 \%$ and $23 \%$, and the linoleic acid level ranged between $8.8 \%$ and $22.5 \%$. Therefore, the fatty acid composition of the most olive oils considered was in keeping with the IOC norms. The Pearson correlation coefficients obtained were found to be negatively significant for the oleic, palmitic and linoleic acid levels recorded. The cluster and principal component analyses performed revealed the importance of fatty acids and polyphenol contents in the clustering of olive ecotypes. The selection of olive ecotypes according to oil quality is possible, requiring further studies focusing especially on their agronomic characters.
\end{abstract}

Key words: olive, oil, phenols, acidity, chlorophyll, carotenes, fatty acids, Tunisia

\section{INTRODUCTION}

Although the olive (Olea europaea L.) is native to the Mediterranean basin, it is now cultivated in Australia and a number of countries of North and South America (Therios, 2009). The early domestication of olives and the use of vegetative propagation methods have resulted in the development of a great number of olive varieties brought about by mutations over a long period of time (Bellini et al., 2008).

In recent years, much work has been done to collect, characterize, evaluate and identify olive germplasm. Around 2,600 cultivars are attributed to the olive (Rugini \& Lavee, 1992), and more than 3,000 synonyms seem to exist (Bartolini et al., 1999). With the project RESGEN (entitled "Conservation, characterization, collection and use of the olive genetic resources"), managed by the International Olive Council including 16 Mediterranean countries, a total of 139 varieties from 23 countries were catalogued (Barranco et al., 2000). Nowadays, this large patrimony is conserved in two gene bank collections: Cordoba (Spain) and Marrakech (Morocco) (Ben Amar et al., 2014).

A number of olive cultivar collections have been established in Tunisia (Msallem et al., 2000), of which the 'Boughrara' olive germplasm collection is considered the most important with up to 147 local cultivars (Ben Amar et al., 2014). Nevertheless, prospective studies on olives continue to be conducted throughout the world. One such study has been recently carried out in the oasis region of Degache, Tunisia (Tozeur, South West Tunisia), resulting in the identification and morphological characterization of 53 local olive ecotypes (Ben Amar et al., 2017). 
The olive cultivars identified were characterized according to the following morphological parameters: tree, leaf, fruit, inflorescence and stone (IOC, 1997). On the basis of the COI descriptors, a number of studies have been conducted on the Tunisian olive germplasm material from different regions of the country relative to the morphological characters of olives (Mehri et al., 1997; Trigui \& Msallem, 2002; Taamalli et al., 2006). The Shannon-Weaver and Nei indices were computed for qualitative parameters, using the phenotypic frequencies to assess the phenotypic diversity for each character. In the oasis region of Degache, the olive leaves were found to be slightly variable since the diversity indices were lower than 0.08 , whereas the descriptors of the olive fruit and endocarp were more variable with the indices exceeding 0.20 (Ben Maachia \& Ben Amar, 2014).

Oil quality is one of the main criteria for the characterization of olive cultivars (De La Rosa et al., 2008; Leon et al., 2008). The definition of olive oil quality is rather complex and is associated with the richness of olive oil aroma, its storability, content of antioxidant compounds, and ratio between saturated and unsaturated acids (Fontanazza \& Bartolozzi, 1998; Lavee \& Avidan, 2000). Several studies have shown the dietary importance of the fatty acid composition of lipids. A healthy diet must contain a limited amount of saturated fatty acids (namely palmitic acid) to reduce the total cholesterol content and a high amount of monounsaturated fatty acids (namely oleic acid) to prevent the risk of cardiovascular diseases, reduce the body's insulin requirements and decrease the plasma concentration of glucose (D'Imperio et al., 2007).

The most important olive cultivar in Tunisia 'Chemlali Sfax' is rich in oil and well adapted to arid conditions (Barranco et al., 2000). Although 'Chemlali Sfax' oil is appreciated for its organoleptic properties, its low oleic acid content and high palmitic acid content are considered disadvantageous (IOC, 1997).

As there is an increasing need for new olive cultivars with high oil quality, the purpose of this study is to examine the physiochemical properties of oils of 17 local olive ecotypes identified in the Tunisian oasis of Degache (Tozeur) in comparison with the most extensively grown cultivar 'Chemlali Sfax'.

\section{MATERIAL AND METHODS}

\section{Plant material}

A total of 17 local olive ecotypes were identified under the palm trees in the Degache oasis in the period 2010-2012. The list of the olive ecotypes identified is presented in Table 1.

Table 1. List of the 17 ecotypes identified in the Degache oasis in the period 2010-2012 and their respective codes

\begin{tabular}{cccc}
\hline Ecotype & Abbrevation & Ecotype & Abbrevation \\
\hline Degache 1 & DG 1 & Degache 27 & DG 27 \\
Degache 3 & DG 3 & Degache 29 & DG 29 \\
Degache 4 & DG 4 & Degache 30 & DG 30 \\
Degache 5 & DG 5 & Degache 31 & DG 31 \\
Degache 6 & DG 6 & Degache 32 & DG 32 \\
Degache 13 & DG 13 & Degache 36 & DG 36 \\
Degache 14 & DG 14 & Degache 40 & DG 40 \\
Degache 15 & DG 15 & Degache 42 & DG 42 \\
Degache 26 & DG 26 & & \\
\hline
\end{tabular}

For each ecotype, one kilogram of olives was harvested at the same maturity stage, i.e. when the fruit skin was light violet in color. The olive fruit samples were immediately subjected to the extraction process that was carried out on a laboratory scale using an experimental oil mill. Each sample was crushed and then mixed for 40 min. After centrifugation, the oil obtained by decantation was transferred into dark glass bottles and stored in the dark at $4{ }^{\circ} \mathrm{C}$ until use.

\section{Methodology \\ Acidity}

Free acidity was determined as stipulated by the European Union Commission Regulations (EEC, 1991). Acidity (Ac) is defined as the percentage of free fatty acids resulting from the hydrolysis of triglycerids and is expressed as oleic acid $(\mathrm{g} / 100 \mathrm{~g}$ of oil). The determination of free fatty acids was done by the titration of a solution of oil dissolved in ethanol/ether $(1: 1, \mathrm{v} / \mathrm{v})$ with a $0.1 \mathrm{M}$ potassium hydroxide ethanolic solution. 


\section{Fatty acid composition}

Analytical methods for the determination of fatty acid composition were described in the regulation EEC 2568/91 (EEC , 1991). Fatty acids were converted to fatty acid methyl esters before analysis by shaking a solution of $0.2 \mathrm{~g}$ oil and $3 \mathrm{ml}$ of hexane with $0.3 \mathrm{ml}$ of $2 \mathrm{~N}$ methanolic potassium hydroxide.

The fatty acid composition of the oils was determined using gas chromatography (GC) as fatty acid methyl esters (FAMEs). FAMEs were prepared by saponification/methylation with sodium methylate according to the European Regulations. A chromatographic analysis was performed in a Hewlett-Packard model 4890D gas chromatograph equipped with a $30 \mathrm{~m} \times 0.25 \mathrm{~mm} \times 0.25 \mu \mathrm{m}$ film thickness fused Silica capillary column (Innowax) coupled to a flame ionization detector (column temperature $210^{\circ} \mathrm{C}$ ). Fatty acids were identified by comparing their retention times with those of standard compounds. In the present study, the major fatty acids (namely oleic acid (Ol), palmitic acid (Pa) and Linoleic acid (Lin)) were expressed in percentage.

\section{Total phenols}

Total phenolic (PP in ppm) content was determined using the Folin-Ciocalteu's colorimetric analysis (Vinha et al., 2005). Phenolic compounds were extracted from $2.5 \mathrm{~g}$ of olive oil dissolved in $5 \mathrm{ml}$ hexane using a solution of methanol and water $(5 \mathrm{ml} ; 60 / 40, \mathrm{v} / \mathrm{v})$. The mixture was then vigorously shaken for $2 \mathrm{~min}$. The Folin-Ciocalteu reagent $(0.5 \mathrm{ml})$ and bi-distilled water $(4.8 \mathrm{ml})$ was added to the phenolic fraction. The mixture was incubated for $2 \mathrm{~h}$ in the dark at room temperature. The absorbance was measured at $725 \mathrm{~nm}$ and expressed as parts per million (ppm) of gallic acid.

\section{Chlorophyll and carotene contents}

The chlorophyll (Chl in ppm) and carotenoid $(\mathrm{Ca}$ in $\mathrm{ppm})$ fractions were evaluated at $670 \mathrm{~nm}$ and $470 \mathrm{~nm}$ respectively, relative to the absorption spectrum of each virgin olive oil sample $(7.5 \mathrm{~g})$ dissolved in cyclohexane $(25 \mathrm{ml})$ (Minguez Mosquera et al., 1990). The chlorophyll and carotene contents are expressed as mg per $\mathrm{kg}$ of oil.

\section{UV absorbance}

The specific coefficients of extinction in ultraviolet at $232 \mathrm{~nm}$ (K232) and $270 \mathrm{~nm}$ (K270) measured using spectrophotometry were determined according to the methods recommended by the International Olive Council and specified in the EU regulation on the characterization of olive oils (EEC, 1991).

\section{Refraction index}

The index of refraction (RI) is a constant that can be used as a ratio in the relationship between the angle of incident and the angle of refraction. The refractive index of a medium is defined as the ratio of the speed of light in vacuum to that in the medium. As the speed of light is highest in vacuum, the index is always greater than 1.

\section{Data analysis}

Database was created using different oil character values, which were subjected to statistical analysis. The descriptive analysis of the results obtained is shown as the mean and the coefficient of variation of independent measurements. The Pearson correlation and principal components analysis (PCA) were performed in order to test the relationship between the traits measured for the different ecotypes considered. The statistical significance of correlation coefficients was evaluated using t-tests at a probability of $1 \%$. The same database was used for the cluster analysis using the unweighted pair-group method of averages (UPGMA) to generate a dendrogram. All the data analyses were performed using XLSTAT 11.0.

\section{RESULTS AND DISCUSSION}

\section{Descriptive analysis}

Table 2 lists the individual values, means and variations of eleven quantitative characters of the olive ecotype oils considered. The variation coefficients ranged from $0.11 \%$ to $127.1 \%$. The highest variation coefficient was noted for the chlorophyll content, whereas the lowest values were recorded as the refraction index (RI). The other traits showed intermediate variability (CV between 10\% and 80\%) among olive ecotype oils.

As acidity and coefficients of extinction (K232 and K270) were the major criteria of oil quality determination (IOC, 2016), most of the oils examined were within the ranges established for the highest quality, i.e. 'extra virgin' olive oil. Therefore, the free acidity was lower than an upper limit of $0.8 \%$, whereas the K232 and K270 absorbance values were lower than the limit allowed by the IOC Regulation: 2.5 and 0.22 , respectively. 
The carotene and chlorophyll contents were widely variable and reached levels as high as $13.6 \mathrm{ppm}$ and $9.1 \mathrm{ppm}$, respectively. The total phenols concentration varied from $71 \mathrm{ppm}$ to $796 \mathrm{ppm}$ across the ecotypes and the maximum value can be considered very high since a maximum of $800 \mathrm{ppm}$ was reported in the literature (Abaza et al., 2005).

For oleic acid, several ecotypes had lower levels (47.1\%) than the minimum needed by the IOC norm (55\%) and other ecotypes exhibited high levels (up to 73\%). For palmitic and linoleic acids, several ecotypes had levels exceeding the limits reported by IOC (1997), i.e. $20 \%$ and $21 \%$, respectively. It is evident that there are several ecotypes with the fatty acid composition conforming to the IOC standards. It is considered that healthy oil must have high oleic acid levels, low palmitic acid levels and moderate linoleic acid levels (Grati-Kamoun \& Khlif, 2001).

As monounsaturated fatty acids of virgin olive oil and the presence of pigments and phenolic compounds make virgin olive oil more stable (EEC, 1991), several ecotypes exhibited higher oil stability than others.

\section{Correlation analysis}

Table 3 shows the Pearson correlation between the oil parameters considered. On balance, the correlations between the parameters were comparatively low and non-significant. Only three correlation coefficients were highly significant for the tested fatty acids: strongest negative correlations were established between oleic acid (C18:1) and both palmitic (16:0) and linoleic acids (C18:2). Therefore, a positive and significant correlation was found between palmitic acid and linoleic acid.

Highly significant correlations between these fatty acids were also reported by Manai et al. (2007) and Zarrouk et al. (2009) for olive hybrids and varieties, suggesting an olive oil-specific property. Moreover, increasing oleic acid levels and decreasing palmitic and linoleic acid levels have been reported during the early maturation period (Zarrouk et al., 2009). A precise harvest date must be chosen for each ecotype in order to obtain an equilibrated acid composition. Olive oil with the most favorable acid composition must have high oleic acid levels, low palmitic acid levels and medium linoleic acid levels (Grati-Kamoun \& Khlif, 2001). These levels are defined by the IOC (1997) norms for each fatty acid.

Table 2. Physicochemical parameters of 17 olive ecotype oils with their means and coefficients of variation

\begin{tabular}{ccccccccccc}
\hline Ecotype & RI & Ca & Ac & Chl & PP & K232 & K270 & Ol & Pa & Lin \\
\hline DG1 & 1.471 & 2.97 & 0.35 & 0.99 & 691.07 & 2.99 & 0.08 & 54.10 & 19.20 & 20.80 \\
DG3 & 1.469 & 2.45 & 0.73 & 0.87 & 796.07 & 2.46 & 0.09 & 73.00 & 11.80 & 10.60 \\
DG4 & 1.471 & 1.65 & 0.82 & 0.94 & 336.08 & 2.33 & 0.06 & 66.30 & 15.60 & 11.20 \\
DG5 & 1.471 & 1.27 & 0.81 & 0.14 & 603.57 & 2.73 & 0.07 & 51.60 & 19.80 & 22.50 \\
DG6 & 1.471 & 2.00 & 1.10 & 0.43 & 395.24 & 2.09 & 0.11 & 62.00 & 14.70 & 18.30 \\
DG13 & 1.471 & 1.92 & 0.55 & 0.45 & 233.58 & 2.74 & 0.09 & 62.30 & 19.00 & 12.00 \\
DG14 & 1.472 & 2.77 & 0.80 & 0.98 & 456.08 & 1.98 & 0.06 & 63.20 & 16.60 & 12.50 \\
DG15 & 1.470 & 5.08 & 0.47 & 3.29 & 226.91 & 2.41 & 0.07 & 64.40 & 15.80 & 12.10 \\
DG26 & 1.468 & 5.67 & 0.47 & 4.02 & 274.41 & 2.19 & 0.06 & 63.30 & 17.00 & 13.10 \\
DG27 & 1.468 & 9.68 & 0.39 & 9.10 & 795.24 & 2.07 & 0.09 & 61.60 & 16.80 & 14.60 \\
DG29 & 1.471 & 12.30 & 0.22 & 7.19 & 200.25 & 2.26 & 0.05 & 64.00 & 16.10 & 12.90 \\
DG30 & 1.472 & 2.47 & 0.48 & 0.55 & 169.41 & 2.56 & 0.09 & 55.60 & 19.50 & 18.50 \\
DG31 & 1.472 & 5.52 & 0.37 & 4.45 & 356.91 & 1.91 & 0.07 & 57.10 & 19.00 & 16.50 \\
DG32 & 1.468 & 3.10 & 0.39 & 0.48 & 76.10 & 2.02 & 0.16 & 66.00 & 16.20 & 8.80 \\
DG36 & 1.472 & 1.90 & 0.40 & 0.86 & 303.58 & 1.79 & 0.07 & 47.10 & 23.40 & 21.20 \\
DG40 & 1.468 & 6.10 & 0.38 & 0.24 & 155.20 & 2.73 & 0.20 & 55.20 & 18.00 & 20.50 \\
DG42 & 1.467 & 13.60 & 0.85 & 0.54 & 71.10 & 2.50 & 0.19 & 53.90 & 19.10 & 20.80 \\
\hline Mean & 1.47 & 4.73 & 0.56 & 2.09 & 361.2 & 2.34 & 0.09 & 60.04 & 17.5 & 15.7 \\
CV (\%) & 0.11 & 79.9 & 42.7 & 127.1 & 64.61 & 14.6 & 47.7 & 10.8 & 14.72 & 28.18 \\
\hline
\end{tabular}

Legend: RI - refraction index; Ca - carotene (ppm); Ac - acidity (g/100g of oil); Chl - chlorophyll (ppm); PP polyphenol (ppm); K232 and K270 - absorbance at 232 and $270 \mathrm{~nm}$; Ol - oleic acid (\%); Pa - palmitic acid $(\%)$; Lin - linoleic acid (\%)

Table 3. Pearson correlations between the physicochemical parameters of the olive ecotype oils considered

\begin{tabular}{cccccccccc}
\hline Parameter & RI & Ca & Ac & Chl & PP & K232 & K270 & Ol & Pa \\
\hline Ca & -0.529 & & & & & & & & \\
Ac & 0.043 & -0.278 & & & & & & \\
Chl & -0.152 & 0.605 & -0.498 & & & & & \\
PP & 0.151 & -0.230 & 0.143 & 0.227 & & & & \\
K232 & 0.526 & -0.204 & -0.006 & 0.295 & 0.295 & & & \\
K270 & -0.453 & 0.231 & 0.103 & -0.189 & -0.312 & -0.263 & & \\
Ol & -0.240 & -0.029 & 0.141 & 0.207 & 0.141 & -0.163 & -0.228 &
\end{tabular}




\begin{tabular}{cccccccccc}
\hline Pa & 0.308 & -0.033 & -0.301 & -0.157 & -0.251 & 0.196 & 0.095 & $-0.918 * *$ & \\
Lin & 0.157 & 0.052 & 0.088 & -0.257 & 0.049 & 0.172 & 0.282 & $-0.901 * *$ & $0.673 * *$ \\
\hline Legend: ** - Significant correlation $(<0.01)$ \\
\hline
\end{tabular}

\section{Hierarchical analysis}

The cluster analysis of the olive oil data obtained was conducted on the Euclidean distance matrix. The resulting dendrogram (Fig. 1) revealed five major groups. The first group includes five ecotypes: Dg 13, Dg 15, Dg 29, Dg 30 and Dg 40. This group also has two subgroups, one of them embracing the Dg 13, Dg 15 and Dg 29 ecotypes which have mainly medium oleic acid rates (62 to 65\%) and phenolic contents (200 to $235 \mathrm{ppm}$ ), whereas the remainder (namely Dg 30 and Dg 40) feature low oleic acid rates (55 to 56\%) and phenolic contents (less than $170 \mathrm{ppm}$ ). The second and third groups consist of four (Dg 1, Dg 3, Dg 5 and Dg 27) and six (Dg 4, Dg 6, Dg 14, Dg 26, Dg 31 and Dg 36) ecotypes, respectively. These ecotypes have oils with very high phenolic contents ranging from 600 to 800 ppm. In contrast with Group 2, the Group 3 ecotypes showed medium to high phenolic contents (274 - $456 \mathrm{ppm})$. The remaining Groups 5 and 6 include only one olive ecotype each. The Group 5 ecotype Dg 32 has a specific oil composition consisting of low phenolic and linoleic acid contents (76 ppm and $8.8 \%$, respectively) and a medium oleic acid percentage (66\%). The last group contains the Dg 42 ecotype, which has low phenolic and oleic acid contents (71 ppm and 54\%, respectively).

Owing to the irregular distribution of the olive ecotypes in the oasis, their clustering was mainly attributed to their genetic performance (namely oil quality) rather than to soil, climatic or cultural factors. Accordingly, it was possible to determine the origin of each olive seedling considered.

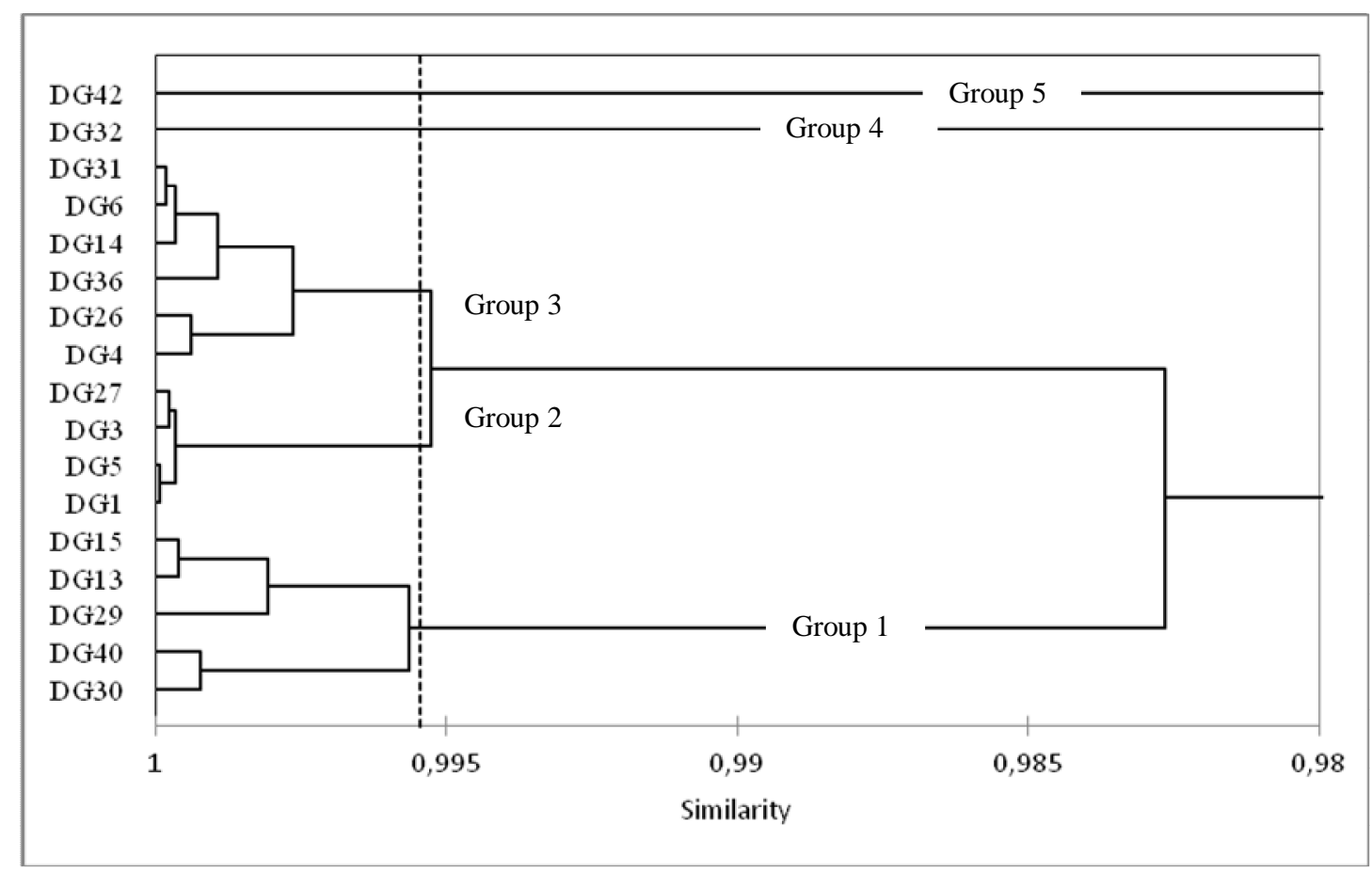

Figure 1. Cluster analysis dendrogram of the olive ecotypes considered using the UPGMA

\section{Principal component analysis}

Principal component analysis showed that the first two principal factors accounted for a $52.87 \%$ share of the total variance (Fig. 2). Factor 1 explained a $29.71 \%$ share of the total variance and was positively correlated with the oleic acid values and negatively with the palmitic and linoleic acid values. Factor 2 accounted for a $23.16 \%$ share of the total variance and was positively correlated with the carotene content and K270 values and negatively correlated with the oil polyphenol contents. Therefore, the following olive ecotypes can be distinguished according to their performance:

- $\quad$ Ecotype DG 3 had the highest oleic acid level.

- Ecotype DG 36 had the highest values of palmitic and linoleic acids.

- Ecotype DG 42 had the highest carotene content. 
- $\quad$ Ecotype DG 40 had the highest for K270 value.

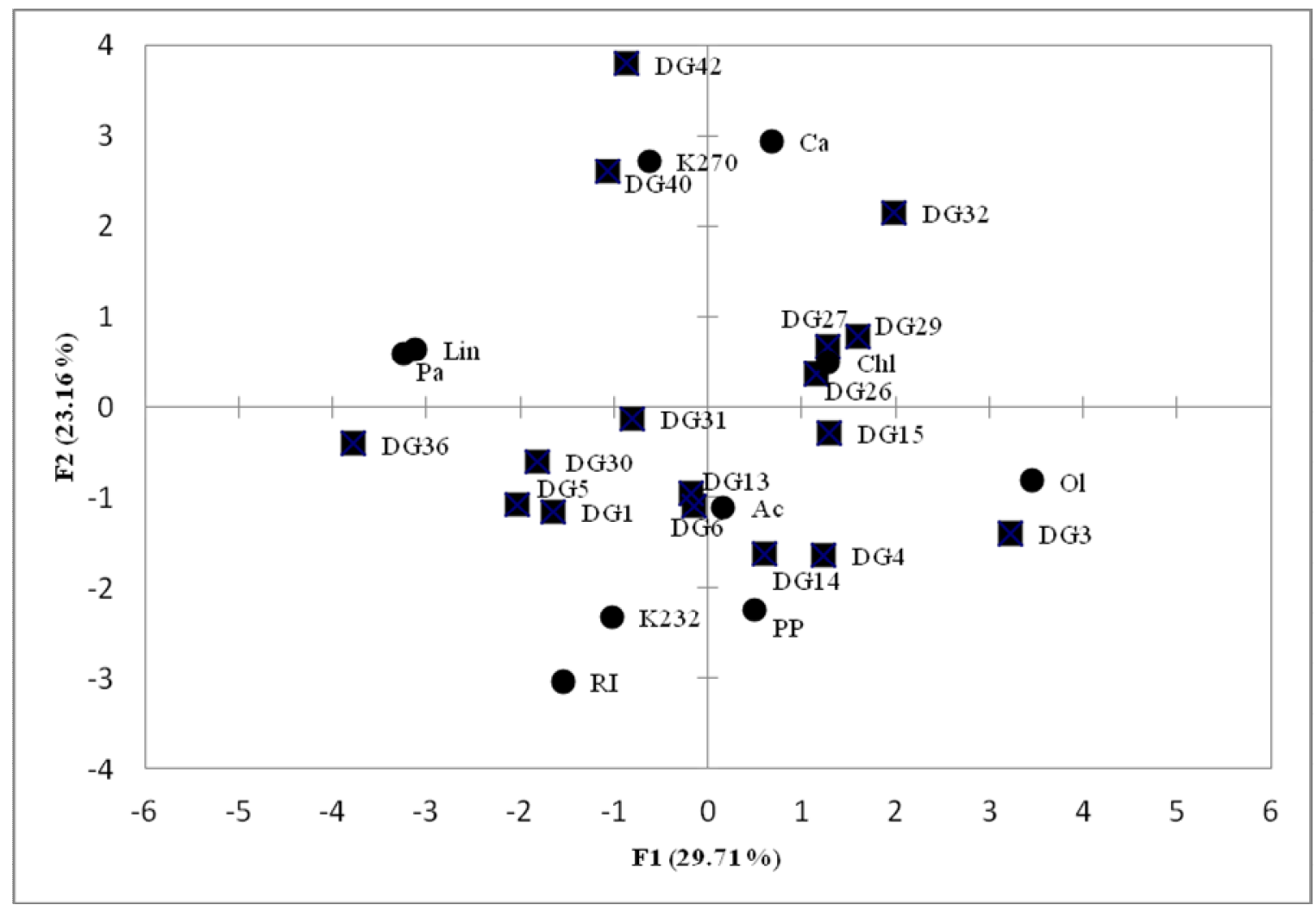

Figure 2. Scatter plot grouping of the olive ecotypes considered based on the first two principal factors of the principal components analysis

\section{CONCLUSION}

This study revealed significant differences between the physicochemical parameters of the olive ecotype oils considered, indicating that olive ecotype selection can be made on the basis of oil quality. This preliminary evaluation can surely be improved by considering other minor chemical components of virgin olive oil such as individual phenolic compounds, volatiles, sterols and alcohols.

\section{Acknowledgments}

The authors wish to thank the Ministry of Agriculture, Hydraulic Resources and Fishery (especially IRESA) and the Ministry of Higher Education and Scientific Research for their financially support to this breeding program.

\section{REFERENCES}

Abaza L., Taamalli W., Ben Temime S., Daoud D., Gutierrez F., Zarrouk M. (2005): Natural antioxidant composition as correlated to stability of some Tunisian virgin olive oils. Rivista Italiana Sostanze Grasse, 82: 12-18.

Barranco D., Cimato A., Fiorino P., Rallo L., Touzani A., Castaneda C., Serafini F., Trijillo I. (2000): World catalogue of olive varieties. Ed: International Olive Oil Council, Madrid, Spain.

Bartolini G., Prevost G., Messeri C., Carignani G. (1999): Olive cultivar names and synonyms and collections detected in a literature review. Acta Horticulturae, 474: 159-162.

Bellini E., Giordani E., Rosati A. (2008): Genetic improvement of olive from clonal selection to cross-breeding programs. Advances in Horticultural Science, 22(2): 73-86.

Ben Amar F., Ayachi Mezghani M., Majeed Yengui A., Benbelkacem N. (2014): Genetic diversity of Arab varieties of olive held in the Boughrara National Olive Germplasm Bank (Sfax, Tunisia). Olivae, 120: 18-22.

Ben Amar F., Ben Maachia S., Yengui A. (2017): Catalogue des ressources génétiques de l'olivier de l'oasis de Degache. Ed: FAO, Rome, Italy. 
Ben Maachia S. \& Ben Amar F. (2014): Prospection, morphological and Pomological identification of olive ecotypes (Olea europaea L.) in the Degache oasis (Tozeur, Tunisia). Journal of New Sciences, 33(2): 1892-1900.

De la Rosa R., Leon L., Moreno I., Barranco D., Rallo L. (2008): Ripening time and fruit characteristics of advanced olive selections for oil production. Australian Journal of Agricultural Research, 59(1): 46-51.

D’imperio M., Dugo G., Alfa M., Mannina L., Segre A. (2007): Statistical analysis on Sicilian olive oils. Food Chemistry, 102: 956-965. doi: 10.1016/j.foodchem.2006.03.003

EEC. (1991): Regulation EEC/2568/91 on the characteristics of olive and olive pomace oils and their analytical methods. Official Journal of European Community, 248: 6-36.

Fontanazza G. \& Bartolozzi F. (1998): Olive. In: Italian contribution to plant genetics and breeding (G.T. Scarasciamugnozza and M.A. Pagnotta, eds). XV Congress of Eucarpia, Viterbo 21-25 September. pp. 723-737.

Grati-Kamoun N. \& Khlif M. (2001): Caractérisation technologique des variétés d'olivier cultivées en Tunisie. Revue Ezzitouna (numéro spécial). $69 \mathrm{p}$.

IOC (1997): Méthodologie pour la caractérisation secondaire des variétés d'olivier, Projet RESGEN, Madrid (Espagne), ed. Conseil Oléicole International. 1997. 10p.

IOC. (2016): Norme commerciale applicable aux huiles d'olive et aux l'huiles de grignions d'olive. T. $15 / \mathrm{NC} \mathrm{n}^{\circ} 3 / \mathrm{Ré}^{\mathrm{v}}$. 6 .

Lavee S. \& Avidan B. (2000): Olive germplasm development past and present approaches to genetic improvement. Acta Horticulturae, 586: 47-56.

Leon L., De la Rosa R., Gracia A., Barranco D., Rallo L. (2008): Fatty acid composition of advanced olive selections obtained by crossbreeding. Journal of the Science of Food and Agriculture, 88(11): 1921-1926.

Manaï H., Mahjoub-Haddada F., Trigui A., Daoud D., Zarrouk. M. (2007): Compositional quality of virgin olive oil from two new Tunisian cultivars obtained through controlled crossings. Journal of the science of food and agriculture, 87 (4): 600 606.

Mehri H., Msallem M., Kamoun-Mehri R. (1997): Identification des principaux cultivars d'olivier cultivés en Tunisie. Plant Genetic Resources Newsletter, 112:68-72.

Minguez Mosquera M.I., Rojas B.G., Fernandez J.G., Guerro L.G. (1990): Pigments present in virgin olive oil. Journal of American Oil Chemistry Society, 67: 192-196.

Msallem M., Radhouane L., Mehri H. (2000): Inventory of olive tree collections in Tunisia. IBPGRI Newsletter, 122: 36-40.

Rugini E. \& Lavee S. (1992): Olive. In: Biotechnology of perennial fruit crop (F.A. Hammerschlag. and R.E. Ltz, eds.). CAB International, Wallingford, UK. pp. 371-382

Taamalli W., Geuna F., Banfi R., Bassi D., Daoud D., Zarrouk M. (2006): Agronomic and molecular analyses for the characterization of accessions in Tunisian olive germplasm collections. Electronic Journal of Biotechnologiy, 9(5): 467481.

Therios I.N. (2009): Olives. Crop Production Science in Horticulture Series. CABI, UK. p. 409.

Trigui A. \& Msallem M. (2002): Oliviers de Tunisie (Volume 1). Ministère de l'Agriculture, IRESA, Institut de l'Olivier, République Tunisienne.

Vinha A.F., Ferreres F., Silva B.M., Valentao P., Goncalves A., Pereira J.A., Oliveira M.B., Seabra R.M., Andrade P.B. (2005): Phenolic profiles of Portuguese olive fruits (Olea europaea L.): Influences of cultivar and geographical origin. Food Chem, 89: 561-568.

Zarrouk W., Baccouri B., Taamalli W., Trigui A., Daoud D., Zarrouk, M (2009): Oil fatty acid composition of eighteen Mediterranean olive varieties cultivated under the arid conditions of Boughrara (southern Tunisia). Grasas y aceites, 60 (5): 498-506.

Submitted: 31.3 .2020 .

Accepted: 15.6.2020. 